\title{
PENGARUH JENIS OLI BEKAS SEBAGAI BAHAN BAKAR KOMPOR PENGECORAN LOGAM TERHADAP WAKTU KONSUMSI DAN SUHU MAKSIMAL PADA PEMBAKARAN
}

\author{
Alif Rivan Hidayat ${ }^{1}$, Basyirun ${ }^{2}$ \\ ${ }^{12}$ Pendidikan Teknik Mesin, Fakultas Teknik, Universitas Negeri Semarang \\ Email: alifteknik15@gmail.com
}

\begin{abstract}
This study aims to determine the influence of distance traveled of used oil on fuel consumption rate and its maximum combustion temperature. In terms of consumption rate, used oil combustion tends to be slow because it must reach a certain point in order to burn. The maximum combustion temperature of used oil is comparable to other ordinary fuels, and it is suitable for use in metal casting. The study concluded that the longer the distance traveled, the faster the fuel consumption rate required. Used oil of $2200 \mathrm{~km}$ distance traveled is the fastest to burn, 0.8 liters in 745 seconds. The slowest to burn is the one with a distance traveled of 1800 $\mathrm{km}$, which burns in 1031 seconds. The farther the distance traveled yields in a lower combustion temperature reached. At a distance traveled of $1800 \mathrm{~km}$, the maximum temperature is $963.3^{\circ} \mathrm{C}$, while at $2200 \mathrm{~km}$, the maximum temperature is $797.5^{\circ} \mathrm{C}$.
\end{abstract}

Keywords: used oil, used oil type, consumption time, maximum temperature

\begin{abstract}
ABSTRAK
Penelitian ini bertujuan untuk mengetahui seberapa besar pengaruh jenis oli bekas terhadap waktu konsumsi bahan bakar dan suhu maksimal pada pembakaran oli bekas. Ditinjau dari segi kecepatan konsumsi bahan bakar, pembakaran oli bekas konsumsinya cenderung lambat karena oli bekas harus mencapai titik tertentu agar dapat terbakar. Ditinjau dari suhu maksimal yang dihasilkan mampu bersaing dengan kompor - kompor dengan bahan lainya dan juga untuk ukuran kompor pengecoran logam sudah memadahi. Pada penelitian tersebut, dapat disimpulkan bahwa semakin jauh jarak tempuh maka semakin cepat/ rendah waktu konsumsi bahan bakar yang diperlukan. Jarak $2200 \mathrm{~km}$ merupakan waktu tercepat untuk menghabiskan 0,8 liter oli bekas dengan waktu 745 detik. Sementara waktu terlama yaitu 1031 detik pada jarak $1800 \mathrm{~km}$. semakin jauh jarak tempuh maka suhu maksimal yang dihasilkan semakin rendah. Pada jarak $1800 \mathrm{~km}$ menghasilkan suhu maksimal mencapai $963,3{ }^{\circ} \mathrm{C}$, sementara jarak $2200 \mathrm{~km}$ hanya mampu menhasilkan suhu maksimal sebesar $797,5{ }^{\circ} \mathrm{C}$.
\end{abstract}

Kata kunci: oli bekas, jenis oli bekas, waktu konsumsi, suhu maksimal

\section{PENDAHULUAN}

Minyak pelumas atau oli merupakan sejenis cairan kental yang berfungsi sebagai pelican, pelindung, pembersih, mencegah terjadinya benturan antar logam pada bagian dalam mesin seminimal mungkin (Hudoyo, 2013).

Secara umum terdapat 2 macam oli bekas, yaitu oli bekas industri (light industrial oil) dan oli hitam (black oil). Oli bekas industri relatif lebih bersih dan mudah dibersihkan dengan perlakuan sederhana, seperti penyaringan dan pemanasan. Oli hitam berasal dari pelumasan otomotif (Raharjo, 2007).

Sejauh ini pemanfaatan oli bekas yang dilakukan oleh masyarakat masih belum maksimal terutama digunakan sebagai bahan bakar. limbah B3 adalah limbah yang sangat berbahaya, karena bersifat korosif, mudah terbakar, mudah meledak, reaktif, beracun, menyebabkan 
infeksi, iritan, mutagenik dan radio aktif (Rachman, 2013).

Pemanfaatan oli bekas belum maksimal disebabkan belum adanya alat yang sesuai dan sempurna untuk memanfaatkan oli bekas sebagai bahan bakar bagi masyarakat. Satu liter oli bekas diperkirakan dapat merusak jutaan liter air segar dari sumber air dalam tanah (Fitriawan, 2010). Pada umumnya oli bekas dimanfaatkan masyarakat dengan berbagai cara seperti daur ulang untuk digunakan lagi dengan cara menambahkan zat kimia untuk memurnikannya. Oli mesin bekas memiliki kandungan logam lebih tinggi dari oli mesin baru, kandungan tersebut antara lain alumunium ( $\mathrm{Al})$, besi ( $\mathrm{Fe})$, tembaga $(\mathrm{Cu})$, mangan $(\mathrm{Mn})$ dan seng $(\mathrm{Zn})$ (Dahlan, 2014).

Namun hasil daur ulang tidak seperti oli yang masih baru. Selain itu digunakan sebagai penghilang karat pada knalpot, sebagai pengawet kayu dan pelumas rantai.

Pada kompor pengecoran logam terjadi pembakaran yang menyebabkan tidak stabilnya suhu pada kompor, perubahan suhu diakibatkan naik dan turunya nyala api pada kompor sehingga menghasilkan produk yang cacat coran. Pada proses pembakaran bahan bakar oli bekas belum diketahui waktu pembakaranya. Hal ini membutuhkan penelitian mengenai waktu pembakaran bahan bakar oli bekas pada kompor pengecoran logam.

Oli bekas digunakan sebagai bahan bakar, oli bekas merupakan salah satu sumber polutan yang dapat mongkontaminasi air tanah, dan akan merusak kandungan air tanah. Selain itu dapat membunuh mikro-organisme di dalam tanah serta minyak pelumas bekas dapat menghambat proses oksidasi biologi dari sistem lingkungan (Asidu, dkk. 2016) Namun, oli bekas tidak dapat mencapai pembakaran yang sempurna, seperti solar maupun bensin. Hal ini terjadi karena oli bekas tidak mudah terbakar sehingga tidak terjadi pengkabutan seperti bahan bakar pada umumnya. atau treatment agar dapat menjadi sebuah bahan bakar.

Berdasarkan permasalahan di atas maka peneliti tertarik untuk mengambil judul penelitian tentang "Pengaruh Jenis Oli Bekas (Jarak Tempuh Perjalanan) Sebagai Bahan Bakar Kompor Pengecoran Logam Terhadap Waktu Konsumsi Dan Suhu Maksimal Pembakaran”.

\section{METODE}

Metode penelitian menggunakan metode eksperimen berbentuk deskriptif, selain itu menggunakan pengujian waktu konsumsi dan suhu pembakaran. Alat yang digunakan dalam penelitian ini adalah mesin las, kompresor, mesin bubut, tap, bor tangan, gerinda tangan, adapun bahan yang digunakan variasi oli bekas, besi ST44, baut dan mur, spuyer, selang tembaga, pressure gauge, kran putar, selang, termokopel tipe K. Termokopel adalah jenis sensor suhu yang digunakan untuk mendeteksi atau mengukur suhu melalui dua jenis logam konduktor berbeda yang digabung pada ujungnya sehingga menimbulkan efek "thermo-electric" (Kho, 2015) dan stopwatch.

Penelitian ini berupa eksperimen, dengan menggunakan metode deskriptif. Metode penelitian tersebut diawali memahami kebutuhan dari perancangan kompor berbahan bakar oli bekas, setelah itu menganalisis masalah dan pernyataan masalah. Bahan yang digunakan dalam penelitian adalah oli bekas dengan SAE 
10W-40 yang digunakan motor serta jarak yang berbeda-beda dan disaring terlebih dahulu sebelum digunakan sebagai bahan bakar kompor oli bekas dan bensin untuk bahan bakar bantu untuk awal penyalaan kompor.

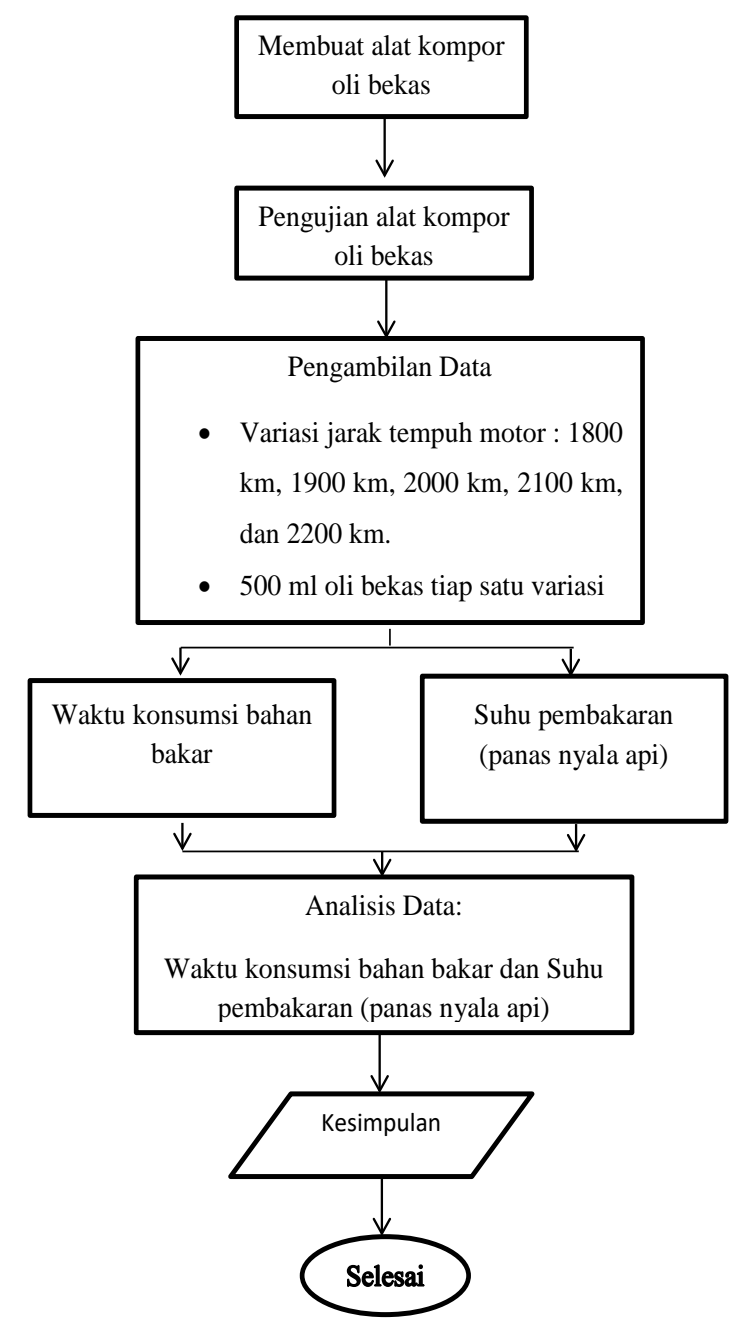

Gambar 1. Diagram alir penelitian

Langkah selanjutnya adalah proses pengambilan data yang dilihat dari segi waktu untuk menghabiskan (konsumsi) bahan bakar dengan berbagai variasi yang sudah ditentukan yang akan disajikan dalam bentuk data tabel dan grafik. Untuk uji suhu pembakaran menggunakan alat termokopel serta data akan disajikan dalam bentuk tabel dan grafik.
Data yang telah didapatkan selanjutnya diolah dan dibuat menjadi sebuah laporan penelitian. Diagram alir penelitian ini bisa dilihat pada Gambar 1.

Penelitian diawali dengan mendesain kompor gas berbahan bakar oli bekas menggunakan software Autodesk Inventor 2015.

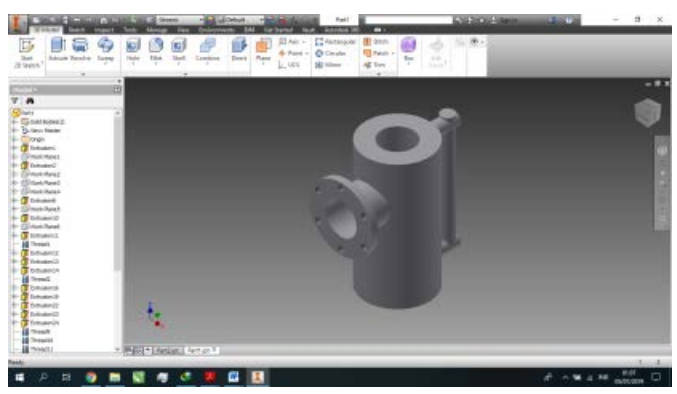

Gambar 2. Proses menggambar menggunakan Autodesk Inventor 2015

Langkah selanjutnya adalah menyiapkan alat dan bahan serta merakitnya menjadi kompor oli bekas. Berikutnya mencoba kompor tersebut dengan tujuan mengecek kinerja dan keamanan pada kompor. Penyaringan oli bekas yang sudah didapat dilakukan dengan tujuan memisahkan geram besi dari oli. Proses pembakaran awal juga dilakukan menggunakan solar/bensin dengan tujuan mempermudah pembakaran pada oli bekas. Setelah api menyala kita dapat menyetel besar kecilnya aliran oli dan juga laju aliran udara pada kompresor. Setelah api menyala tuangkan variasi oli bekas sebesar 0,8 liter. Pengambilan data waktu konsumsi bahan bakar menggunakan stopwatch dari aplikasi hp. Untuk pengujian temperatur pembakaran diambil dengan menggunakan alat termokopel untuk mengukur temperaturnya. 


\section{HASIL DAN PEMBAHASAN}

Waktu konsumsi diperoleh dari pembakaran bahan bakar oli bekas sebanyak 0,8 liter. Tabel 1 menunjukkan waktu konsumsi variasi bahan bakar pada proses pembakaran oli bekas.

Tabel 1. Instrumen Hasil Perhitungan Waktu Konsumsi

\begin{tabular}{ccc}
\hline $\begin{array}{c}\text { Variasi Jarak } \\
\text { Tempuh } \\
(\mathrm{Km})\end{array}$ & $\begin{array}{c}\text { Jumlah } \\
\text { Bahan Bakar } \\
(\mathrm{L})\end{array}$ & $\begin{array}{c}\text { Waktu } \\
\text { Konsumsi }\end{array}$ \\
\hline $1800 \mathrm{~km}$ & 0,8 & 1031 detik \\
$1900 \mathrm{~km}$ & 0,8 & 849 detik \\
$2000 \mathrm{~km}$ & 0,8 & 835 detik \\
$2100 \mathrm{~km}$ & 0,8 & 784 detik \\
$2200 \mathrm{~km}$ & 0,8 & 745 detik \\
\hline
\end{tabular}

Tabel 1 menunjukkan bahwa semakin dekat variasi jarak tempuh bahan bakar maka semakin lama waktu konsumsinya. Data ini diambil dengan menggunakan kompor oli bekas yang telah dibuat. Pengukuran waktu konsumsi bahan bakar oli bekas menggunakan stopwatch, waktu dihitung ketika kompor sudah menyala.

Pencatatan waktu konsumsi bahan bakar oli bekas dilakukan ketika api sudah mulai menyala hingga api tersebut padam. Pengukuran ini dihitung menggunakan aplikasi stopwatch yang ada di handphone. Variasi jenis oli bekas yang digunakan berdasarkan jarak tempuhnya yaitu 1800 km, 1900 km, 2000 km, 2100 km, 2200 $\mathrm{km}$.

Tabel 2 menunjukkan bahwa semakin dekat variasi jarak tempuh bahan bakar maka semakin tinggi suhu maksimalnya. Data ini diambil dengan menggunakan kompor oli bekas yang telah dibuat. Pengukuran suhu maksimal bahan bakar oli bekas menggunakan termokopel, waktu dihitung ketika kompor sudah menyala.

Tabel 2. Instrumen Hasil Pengujian Suhu Pembakaran

\begin{tabular}{cc}
\hline $\begin{array}{c}\text { Variasi Jarak } \\
\text { Tempuh }(\mathrm{Km})\end{array}$ & $\begin{array}{c}\text { Temperatur } \\
\text { Maksimal }\left({ }^{\circ} \mathrm{C}\right)\end{array}$ \\
\hline $1800 \mathrm{~km}$ & 963,3 \\
$1900 \mathrm{~km}$ & 910,6 \\
$2000 \mathrm{~km}$ & 874,9 \\
$2100 \mathrm{~km}$ & 827,5 \\
$2200 \mathrm{~km}$ & 797,5 \\
\hline
\end{tabular}

Dari Gambar 3 didapatkan persamaan garis $\mathrm{t}=-0,637(\mathrm{~s})+2122,8$. Dalam persamaan tersebut terdapat hubungan yang berbanding terbalik, persamaan garis t (waktu konsumsi bahan bakar) dipengaruhi oleh koefisien jenis oli bekas. Koefisien -0,637 artinya terjadinya penurunan waktu konsumsi bahan bakar sebesar 0,637 terhadap jenis oli bekas ditambah dengan konstanta. Sedangkan konstanta 2122,8 merupakan faktor luar atau faktor penambah yang salah satunya yaitu kekentalan (viskositas) pada oli bekas. Persamaan tersebut hanya berlaku pada jarak 1800-2200 km. Berdasarkan persamaan tersebut dapat dilihat bahwa $\mathrm{R}^{2}$ sebesar 0,839. $\mathrm{R}^{2}$ merupakan sumbangan pengaruh jenis oli bekas (s) terhadap t yaitu sebesar $83,9 \%$. Nilai $17.1 \%$ merupakan faktor luar yang salah satunya yaitu kekentalan (viskositas) yang telah dibuktikan pada persamaan garis di atas. Pada jenis oli bekas dengan jarak 1800 km waktu konsumsi yang dibutuhkan untuk menghabiskan oli bekas 0,8 liter adalah 1031 detik yang merupakan waktu paling lama dari semua jenis oli bekas. Pada jenis oli bekas dengan jarak 2200 km diperlukan waktu 745 detik dan waktu tercepat untuk menghabiskan 0,8 liter oli bekas. 


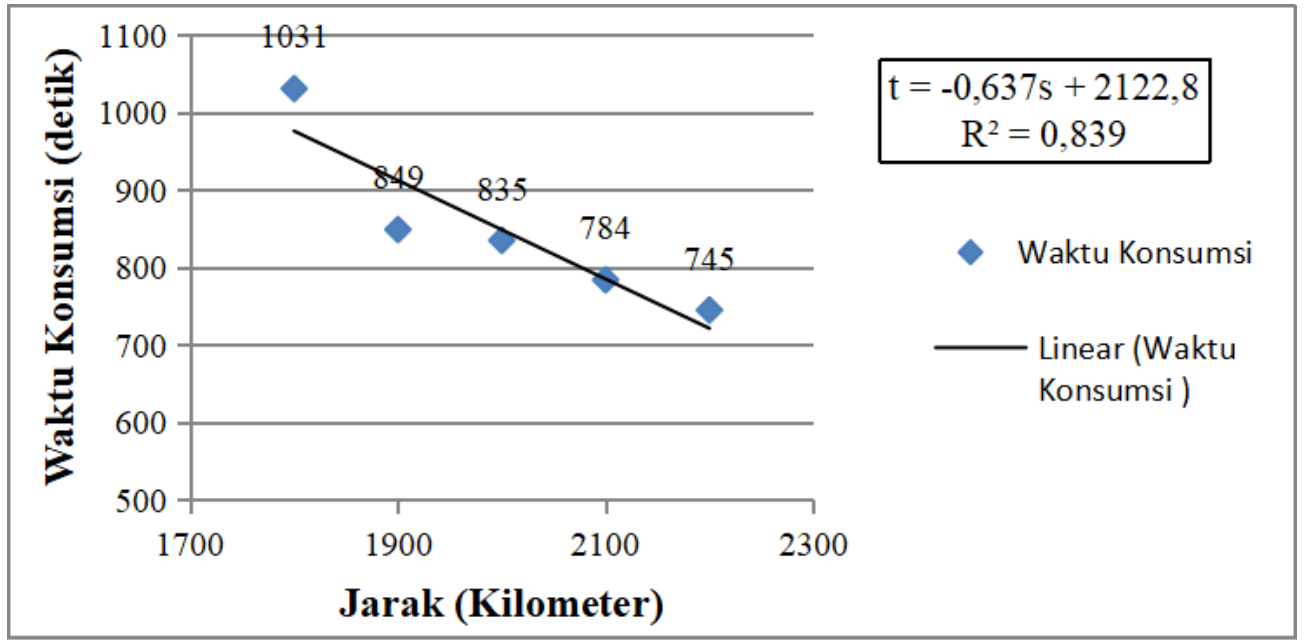

Gambar 3. Pengaruh jenis oli bekas terhadap konsumsi waktu bahan bakar

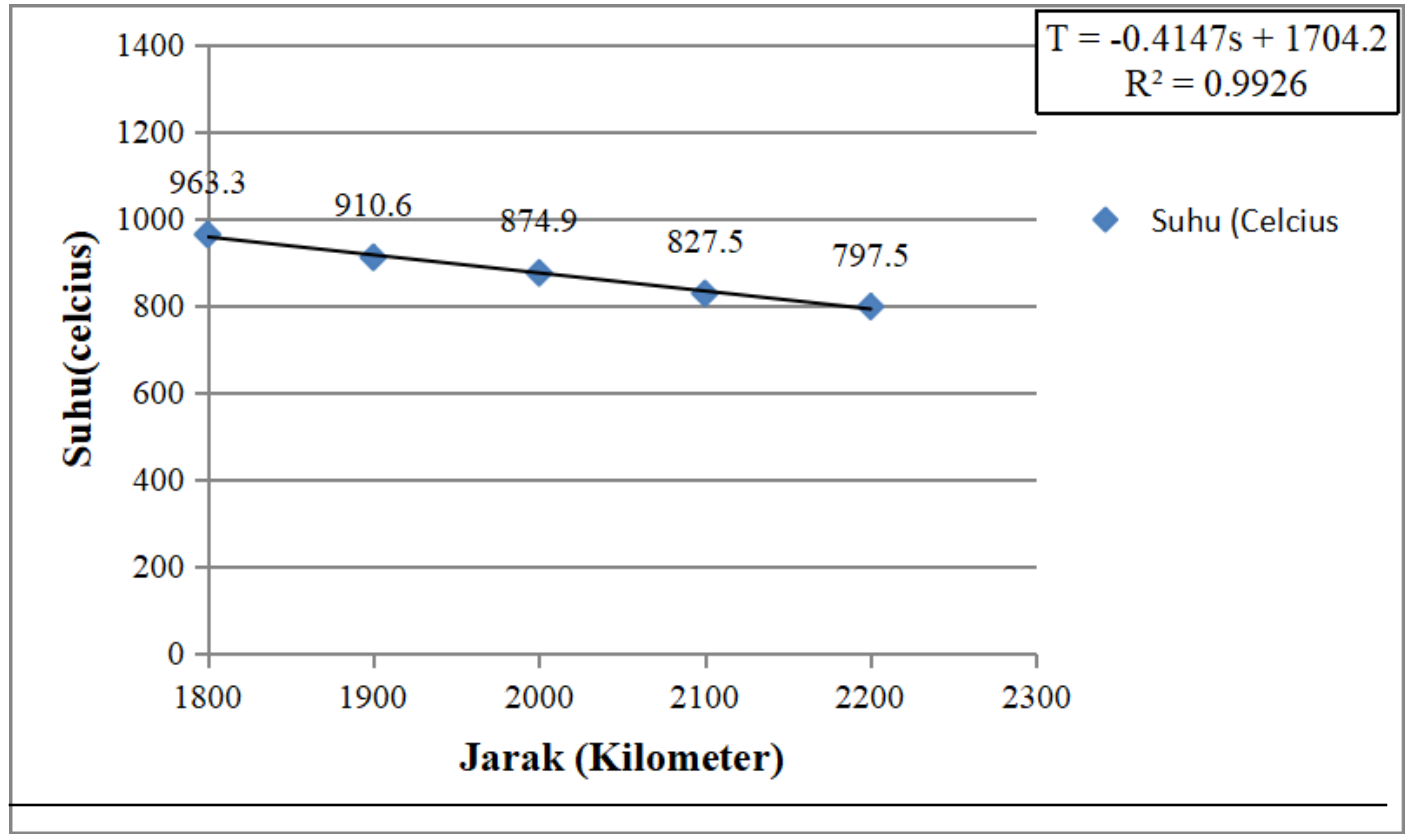

Gambar 4. Pengaruh jenis oli bekas terhadap temperatur maksimal

Dari Gambar 4 didapatkan persamaan garis $\mathrm{T}=-0.4147(\mathrm{~s})+1704.2$. Dalam persamaan tersebut terdapat hubungan terbalik, persamaan garis $\mathrm{T}$ (Suhu oli bekas) dipengaruhi oleh koefisien jenis oli bekas. Koefisien 0.4147 artinya terjadinya penurunan waktu konsumsi bahan bakar sebesar 0.4147 terhadap jenis oli bekas ditambah dengan konstanta. Sedangkan konstanta 1704.2 merupakan faktor luar atau faktor penambah yang salah satunya yaitu kekentalan (viskositas) pada oli bekas. Persamaan tersebut hanya berlaku pada jarak 1800-2200 km. Berdasarkan persamaan tersebut dapat dilihat bahwa $\mathrm{R}^{2}$ sebesar 0.9926. $\mathrm{R}^{2}$ merupakan sumbangan pengaruh jenis oli bekas (s) terhadap Waktu Konsumsi Bahan Bakar (t) yaitu sebesar 99,26\%. Nilai $1,74 \%$ merupakan faktor luar yang salah satunya yaitu kekentalan (viskositas) yang telah dibuktikan pada persamaan garis di atas. 


\section{SIMPULAN}

Simpulan yang diperoleh dari penelitian ini adalah sebagai berikut.

1. Semakin dekat jarak tempuh yang divariasikan maka waktu yang dibutuhkan untuk menghabiskan bahan bakar semakin lama. Hal ini dikarenakan pembakaran dengan oli variasi jarak dekat lebih baik sehingga membuat pembakaran sempurna. Jarak bahan bakar oli sebesar 2200 km merupakan waktu tercepat untuk menghabiskan 0,8 liter oli bekas dengan waktu 745 detik sementara waktu terlama yaitu 1031 detik.

2. Semakin jauh jarak tempuh yang divariasikan maka temperatur maksimal yang dihasilkan semakin rendah. Hal ini dikarenakan kandungan geram pada oli semakin banyak sehingga menjadikan pembakaran tidak sempurna. Pada jarak $1800 \mathrm{~km}$ temperatur maksimal mencapai 963,3 ${ }^{0} \mathrm{C}$ sementara jarak $2200 \mathrm{~km}$ temperatur maksimalnya adalah $797,5^{\circ} \mathrm{C}$.

Saran yang disampaikan berdasarkan temuan di lapangan adalah sebagai berikut.

1. Penulis menganjurkan adanya tempat penampungan bahan bakar oli bekas yang lebih besar untuk menampung bahan bakar oli bekas dengan kapasitas yang lebih banyak. Oleh sebab itu, penulis menggunakan oli bekas hanya sebesar 0,8 liter, karena itu penambahan besarnya tempat oli bekas dapat menjadi solusi. Membuat kompor yang memiliki spek yang sama namun tidak menimbulkan kebisingan (polusi suara).

2. Sulitnya mengukur suhu menggunakan termokopel dikarenakan panas dari api kompor, maka solusinya adalah menggunakan tongkat yang bertujuan untuk alat menempelnya ujung kabel termokopel sehingga mengurangi panas.

3. Bagi yang tertarik dengan penelitian ini, penulis menganjurkan untuk menambahkan flowmeter untuk pengukuran kecepatan aliran oli bekas sehingga bisa melengkapi data yang akan di teliti.

\section{DAFTAR RUJUKAN}

Asidu, dkk. 2016. Pemanfaatan Minyak Oli Bekas Sebagai Bahan Bakar Alternatif engan Pencampuran Minyak Pirolisis. Universitas Halu Oleo. Kendari.

Dahlan, M.H, dkk. 2014. Pemisahan Oli Bekas dengan Menggunakan Kolom Filtrasi dan Membran Keramik Berbahan Baku Zeolit dan Lempung. Jurnal Teknik Kimia 1(20): 38-45.

Fitriawan, D. 2010. Studi pengelolaan limbah padat dan limbah cair PT X- Pasuruan sebagai upaya penerapan proses produksi bersih. Institut Teknologi Sepuluh Nopember. Surabaya.

Kho, D. 2015. Pengertian Termokopel dan prinsip kerjanya.

http://teknikelektronika.com/pengertiantermokopel-thermocouple-dan-prinsipkerjanya/ 20 september 2019. (22.12)

Rachman, A.M. 2013. Manajemen Terhadap Limbah Bengkel. Fakultas Teknologi Industri, Jurusan Teknik Mesin. Universitas Gunadarma. Depok.

Raharjo, W. P. 2004. Pemanfaatan Oli Bekas Sebagai Salah Satu Alternatif Solusi Untuk Mengurangi Kebutuhan Minyak Bakar. Jurnal Mekanika, 3(1) : 23 -25

Roy, Hudoyo dkk. 2013. Pengujian Pengaruh Penambahan Material Pengotor Oli Bekas Jenuh Sebagai Identifikasi Kandungan Energi Pada Oli Murni. Universitas Kristen Satya Wacana. 